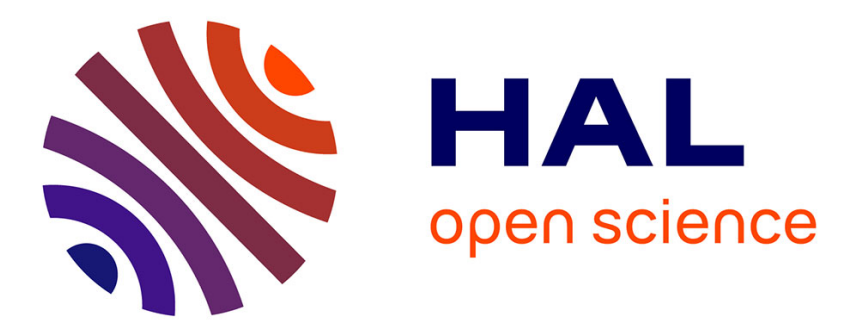

\title{
Quantitative morphometric study of thoracic spine A preliminary parameters statistical analysis
}

Sébastien Laporte, David Mitton, B. Ismael, M. de Fouchecour, J. P. Lasseau, François Lavaste, Wafa Skalli

\section{- To cite this version:}

Sébastien Laporte, David Mitton, B. Ismael, M. de Fouchecour, J. P. Lasseau, et al.. Quantitative morphometric study of thoracic spine A preliminary parameters statistical analysis. European Journal of Orthopaedic Surgery \& Traumatology, 2000, 10 (2), pp.85-91. 10.1007/BF02803102 . hal-03138819

\author{
HAL Id: hal-03138819 \\ https://hal.science/hal-03138819
}

Submitted on 11 Feb 2021

HAL is a multi-disciplinary open access archive for the deposit and dissemination of scientific research documents, whether they are published or not. The documents may come from teaching and research institutions in France or abroad, or from public or private research centers.
L'archive ouverte pluridisciplinaire HAL, est destinée au dépôt et à la diffusion de documents scientifiques de niveau recherche, publiés ou non, émanant des établissements d'enseignement et de recherche français ou étrangers, des laboratoires publics ou privés. 


\title{
Quantitative morphometric study of thoracic spine. A preliminary parameters statistical analysis
}

\author{
S. Laporte 1, D. Mitton 1, B. Ismael 1, M. de Fouchecour 1,.P. Lasseau ${ }^{2,}$ F. Lavaste ${ }^{1}$ and W. Skalli ${ }^{1}$ \\ ${ }^{1}$ Laboratoire de Biomecanique, ENSAM C.E.R de Paris, 151, bid de l'Hopital, F-75013 Paris, France \\ ${ }^{2}$ Institut d'Anatomie, Faculte de Medecine des Saints-Peres, 45, rue des Saints-Peres, F-75006 Paris, France
}

Summary: Study Design: A quantitative morphometric study of the thoracic spine from $\mathrm{Tl}$ to $\mathrm{T} 12$ was conducted on 50 dried spines. Objective: To quantify anatomic descriptive parameters concerning thoracic vertebrae, and to investigate statistical correlation between some of them, in order to 1) refine knowledge of some dimensions and orientations for clinical applications 2) aid for implant's designing, and, 3) improve existing geometric and mechanical models or 3D reconstruction techniques concerning thoracic spine. Summary of Background Data: A few three-dimensional quantitative studies were performed, either on a limited number of parameters, or on a limited series of specimens. No investigation of statistical correlation between parameters was previously performed concerning thoracic vertebrae. Methods: 373 thoracic vertebrae from 50 dried spines were considered. Three spatial coordinates of 140 points spread on the surface for each vertebrae (130 for Tio, 120 for $\mathrm{Tu}$ and $\mathrm{T} 12)$ were measured using an electromagnetic system (FASTRAK ${ }^{\circledR}$, estimated accuracy: $\pm 0.4 \mathrm{~mm}$ ). Descriptive parameters were then calcu-

Code Meary: 6011.0

Correspondence to: S. Laporte lated using Excel $^{\circledR}$ and statistical correlation was investigated using xISTAT ${ }^{\oplus}$. Results: The mean values and standard deviations of 81 linear, angular and surfacic parameters were obtained for the thoracic vertebrae on each level. High correlation was found for some parameters, such as interarticularis facet position, pedicles height and width, with the dimensions of the vertebral bodies that can be measured on X-rays. Conclusion: A detailed and accurate quantitative description of thoracic vertebrae is provided. For the first time, statistical correlation is demonstrated between some descriptive parameters which are visible on X-rays, and others which are not.

Key words: Thoracic vertebrae - Morphomet $_{\mathrm{ry}}$ - Correlation

Accurate quantitative morphometry of vertebrae may be needed for several purposes: geometric dimensions, for implant design or surgical acts planning, as well as for basic purpose such as constructing realistic spine model [3] or a geometric database for specific 3D reconstruction techniques from $\mathrm{x}$-rays [8]. A part of these studies were made on scoliotic spine $[5,6,7]$. At present, morphometric measurements were merely performed either on a limited set of parameters $[1,10]$ or on a limited set of vertebrae [9].
Moreover, those measurements can hardly be performed using medical images, only using CT scans or 3D reconstruction from stereo-X Rays, which both may be presently too sophisticated for clinical routine.

The purpose of the present study is, first, to perform extensive measurements of the thoracic vertebrae from $\mathrm{Tl}$ to T12, then to assess statistical correlation between those parameters which are hard to measure on X Rays and those which can be obtained on $\mathrm{X}$ Rays.

\section{Materials and methods}

\section{Materials}

$373 d_{r y}$ thoracic vertebrae from 50 adult thoracic spines were obtained from the Laboratoire d'Anatomie, Musee Orfila, de la Faculte de Medecine des Saints-Peres in Paris, France. Sex, age and origin were unknown. All selected vertebrae were intact, without neither pathologic deformations or broken parts due to conservation. At least 20 vertebrae were considered per vertebral level (ranging from 20 for T10 level, to 36 for Ts) were considered.

\section{Measurement set up}

The dried vertebrae were directly measured with an electromagnetic device Polhemus Fastrak ${ }^{\circledR}$, allowing the 3D 


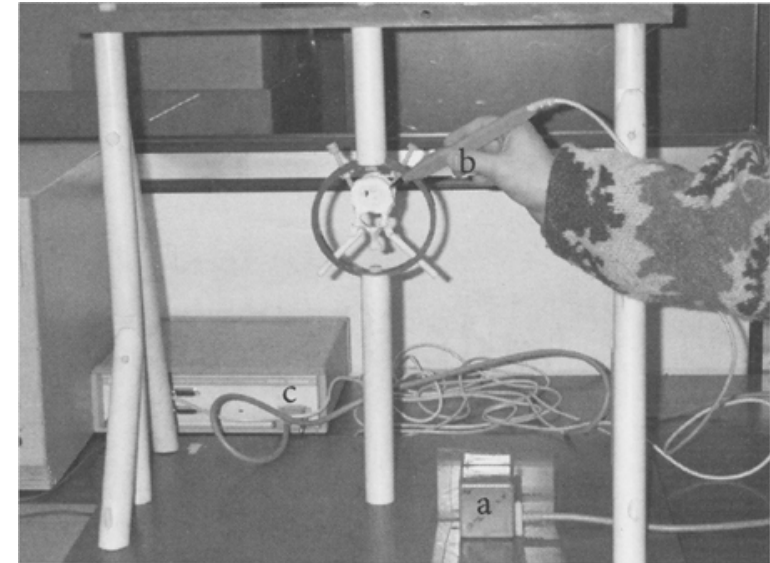

Fig. 1

Measurement set up: a) Emission Cube System, b) Pointer, c) Electronic Device System connected to the $\mathrm{PC}$

Table 1. Parameters nomenclature

\begin{tabular}{|c|c|c|c|}
\hline Anatomical part & Mnemonic & Unit & Description \\
\hline \multirow[t]{3}{*}{ Global parameters } & TPY & $\mathrm{mm}$ & Half lateral vertebra width \\
\hline & TPZ & $\mathrm{mm}$ & $\begin{array}{l}\text { Transverse apophyse extremity position versus mid- } \\
\text { transverse plane }\end{array}$ \\
\hline & SPL & $\mathrm{mm}$ & Postero-anterior vertebra length \\
\hline \multirow[t]{5}{*}{ Vertebral body } & VBH & $\mathrm{mm}$ & Vertebral body height \\
\hline & EPD & $\mathrm{mm}$ & End-plate depth \\
\hline & EPW & $\mathrm{mm}$ & End-plate width \\
\hline & EPA & $\mathrm{mm}^{2}$ & End-plate area \\
\hline & EPI & $\circ$ & $\begin{array}{l}\text { End-plate inclination with regard to the mid-transverse } \\
\text { plane }\end{array}$ \\
\hline \multirow[t]{2}{*}{ Neural canal } & $\mathrm{SCD}$ & $\mathrm{mm}$ & Spinal canal depth \\
\hline & SCW & $\mathrm{mm}$ & Spinal canal width \\
\hline \multirow[t]{8}{*}{ Facets interarticularis } & $\mathrm{SA}$ & $\circ$ & Inclination with regard to the sagittal plane \\
\hline & TA & $\cdot$ & Inclination with regard to the transverse plane \\
\hline & GDSA & $\mathrm{mm}$ & Width of the facet \\
\hline & PDSA & $\mathrm{mm}$ & Depth of the facet \\
\hline & FCA & $\mathrm{mm}^{2}$ & Facet area \\
\hline & CA X & $\mathrm{mm}$ & Distance from the facet centre to the frontal plane \\
\hline & CA Y & $\mathrm{mm}$ & Distance from the facet centre to the sagittal plane \\
\hline & $\mathrm{CAZ}$ & $\mathrm{mm}$ & $\begin{array}{l}\text { Distance from the facet centre to the mid-transverse } \\
\text { plane }\end{array}$ \\
\hline \multirow[t]{6}{*}{ Pedicles } & PDIs & $\cdot$ & Pedicle inclination with regard to sagittal plane \\
\hline & PDIh & $\circ$ & Pedicle inclination with regard to mid-transverse plane \\
\hline & PDL & $\mathrm{mm}$ & $\begin{array}{l}\text { Pedicle length from the vertebral wall to the posterior } \\
\text { arch }\end{array}$ \\
\hline & PDW & $\mathrm{mm}$ & Pedicle width \\
\hline & PDH & $\mathrm{mm}$ & Pedicle height \\
\hline & PDZ & $\mathrm{mm}$ & $\begin{array}{l}\text { Distance from the pedicle lower base to the mid- } \\
\text { transverse plane }\end{array}$ \\
\hline
\end{tabular}

Suffix definitions

$a, p$; Anterior, Posterior

inf, sup; Inferior, Superior

$m$; Measured in the mid-transverse plane

direct measurement of complex shape objects, by means of a pointer. For this specific study, accuracy was estimated at $\pm 0.4 \mathrm{~mm}$ [7]. A specific non-metallic set up (PVC, PolyVinyl Chloride) was used for vertebral positioning. It was constituted of a ring fixed to vertical bars connecting to a horizontal pla- te. A rigid connection between the vertebra and the ring was insured using four PVC screws. The electromagnetic field emission device, fixed on this horizontal plate (Fig. 1), constitutes the referential in which the three-dimensional coordinates of the pointer were recorded.
132 parameters were used to extensively define the thoracic vertebral morphometry. Some of those parameters and their description are presented in Table 1 and in Figure 2. These parameters may be either linear, such as the pedicle width or vertebral posterior and anterior height, or they may be angular (for example pedicle orientation with regard to sagittal plane or to transverse plane), or surfacic. In order to quantify those parameters, points were spread on the surface of each vertebra, respectively 140 points from $T_{1}$ to $T_{9}, 130$ points for $T_{10}$ and 120 for T11 and T12. Density of points in each region depends both on the complexity of the shape and on the importance of this region from a clinical (Pedicle length for screw fixing) or biomechanical point of view (Surface interarticularis for contact study). After vertebral fixation on the measurement set up, point's coordinates measurement was performed with a predefined sequence.

\section{Data processing}

Excel ${ }^{\circledR}$ software was used on a PC for data processing. First a common vertebral coordinate system was defined in order to express the measurements. It was defined using the three local anatomic planes: respectively sagittal $(\mathrm{xOz})$, frontal $(\mathrm{yOz})$ and mid-transverse (xOy) (Fig. 2).

As for the origin of the vertebral referential $(O)$, let Ops and Opi be the "centres" of the superior and inferior endplates, defined in the sagittal plane, at $1 / 2$ of the posterior vertebral wall. $O$ was situated at the middle of the line defined by these two points.

\section{Quantification of parameters}

Linear parameters were simply calculated using the distance between two measured points. Angular parameters were defined by the angles between the reference planes and a plane or an axis describing an anatomical part of the vertebrae. As plane surfaces were described using more than three points, a least square algorithm was used to construct 


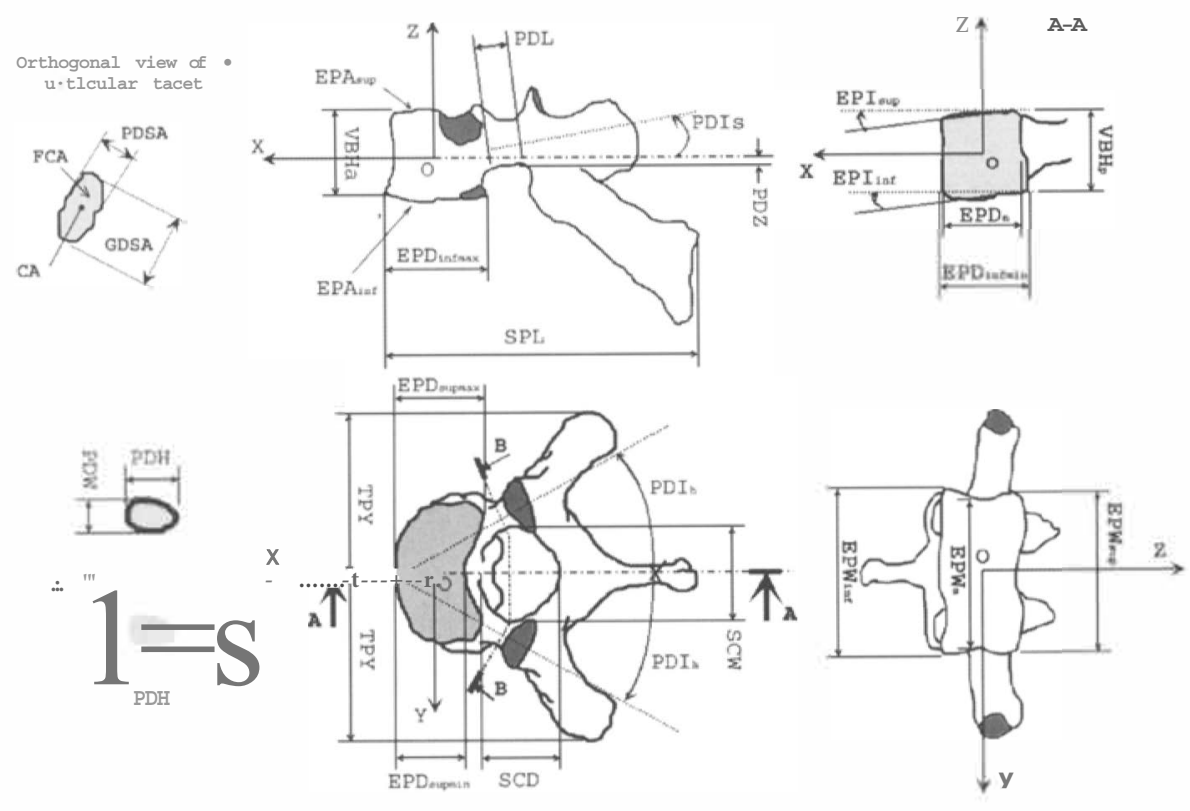

Fig. 2

Parameters description

these planes. The surfacic parameters were calculated with the sum of the areas of each triangle defined by three points of the anatomical surface.

\section{Statistical study}

The 132 parameters measured on each vertebrae, including left and right measurements, were reduced to 81 parameters assuming the symmetry of the vertebrae. The statistical analysis was performed using Excel $^{\oplus}$ and xlSTAT $^{\odot}$ software on a PC.

A multi-linear regression study was performed on each thoracic vertebrae level in order to find relationship between 15 dimensions which can be measured on X-rays (VBHa, VBHp, EPD sup max, EPD sup min, EPDm, EPD inf max, EPD inf min, EPW sup, EPWm, EPW inf, EPI sup, EPI inf, seW, TPZ and TPY, see table 1 for their descriptions) and the other parameters which are less easy to evaluate (as pedicle height and width or facets interarticularis area). Previously an Principal Components Analysis (PCA) was realised in order to evaluate relations between those 15 regression parameters.

\section{Results}

\section{General results}

The means and standard deviations (o) were calculated for all the parameters. As an example these data are exposed in Fig. 3 for the main parameters, according to the vertebral level, and focusing on differences either between anterior and posterior data, or between superior and inferior ones.

\section{Global vertebral dimensions}

An inverse evolution of the global length and width of the thoracic vertebrae is observed (Fig. 3-a). For T12 vertebrae the length/width ratio is $75 \%$ while it is $148 \%$ at Tl level. Evolution for these parameters is not linear along the thoracic spine. Length mean value goes from 71 (o: 3.9$) \mathrm{mm}$ to 65 (o: 4.9) $\mathrm{mm}$ for the vertebrae T12 to $T B$ while it goes from 62 (o: 5.6) $\mathrm{mm}$ to 58 (o: 4.2) $\mathrm{mm} \mathrm{T7}$ to Ti. As for width $\mathrm{T} 12$ and $\mathrm{Tu}$ have relatively smaller values (respectively 48, o: $2.4 \mathrm{~mm}$ and $51 \mathrm{o:}: 2.7 \mathrm{~mm}$ ) while $\mathrm{T} 2$ and Ti have greater ones (respectively 70 , CI: $2.3 \mathrm{~mm}$ and 78, CT: $2.2 \mathrm{~mm}$ ). Standard deviation appears smaller for the vertebral width than for the vertebral length.

\section{Vertebral body}

Vertebral body height (Fig. 3-b) decreases from T12 (posterior 27, CT: 19 $\mathrm{mm}$ and anterior $24, \mathrm{CT}: 1.3 \mathrm{~mm}$ ) to $\mathrm{Tl}$ (posterior 17, CT: $12 \mathrm{~mm}$ and anterior 15, CI: $1.7 \mathrm{~mm}$ ). Posterior height is always greater than anterior one, which is related to thoracic $\mathrm{k}_{\mathrm{y} p}$ hosis. However difference between those parameters does not evolve regularly along the thoracic spine. On the contrary the end-plate depth decreases regularly from T12 (inferior 32, CT:3.3 $\mathrm{mm}$ and superior 34 , CI:3.1 mm) to Tl (inferior 19, CT:2.2 mm and superior 18, o: $1.8 \mathrm{~mm}$ ) (Fig. 3-c). Slight differences (less than $1.5 \mathrm{~mm}$ ) appear between depth of upper and lower end-plates, either of a given vertebra or of adjacent vertebrae. Standard deviation varies from 2 to $3.5 \mathrm{~mm}$ which indicates a large inter-individual variability, extreme values for vertebral depth vary from 23 to $40 \mathrm{~mm}$ for T12 vertebra. As for vertebral end-plate inclination with regards to the mid-transverse plane, a very large inter-individual dispersion is observed (Fig. 3-d).

\section{Neural canal}

Neural canal depth remains quite stable all along the thoracic spine (mean value ranging from $16.5, \mathrm{CT}: 15 \mathrm{~mm}$ to 14.9 , o: $13 \mathrm{~mm}$ ). Canal width is also stable from T10 to T2 (around $14.5 \pm 1 \mathrm{~mm}$ ), while it increases at extreme levels (19.8, CT:13 $\mathrm{mm} ; 16.8$, CT: $13 \mathrm{~mm}$; 18.0 , o: $1.8 \mathrm{~mm}$, respectively for T12, Tn and T1). Only a slight inter-specimen variability was observed (standard deviation ranging from 1.1 to $1.7 \mathrm{~mm}$ ) (Figure 3-e).

\section{Facets interarticularis}

T12 vertebral inferior facet angulation with regard to the sagittal was found smaller than at the other levels (30, CT: $3-7^{\circ}$ ), at these other levels both upper and lower facet orientation with regard to the sagittal plane have similar mean values ranging from 69 to $80^{\prime}$ with a standard deviation ranging from 3.5 to $14.8^{\circ}$. As for facet orientation with regard to the transverse plane, its mean value is nearly the same from T12 to Ts 

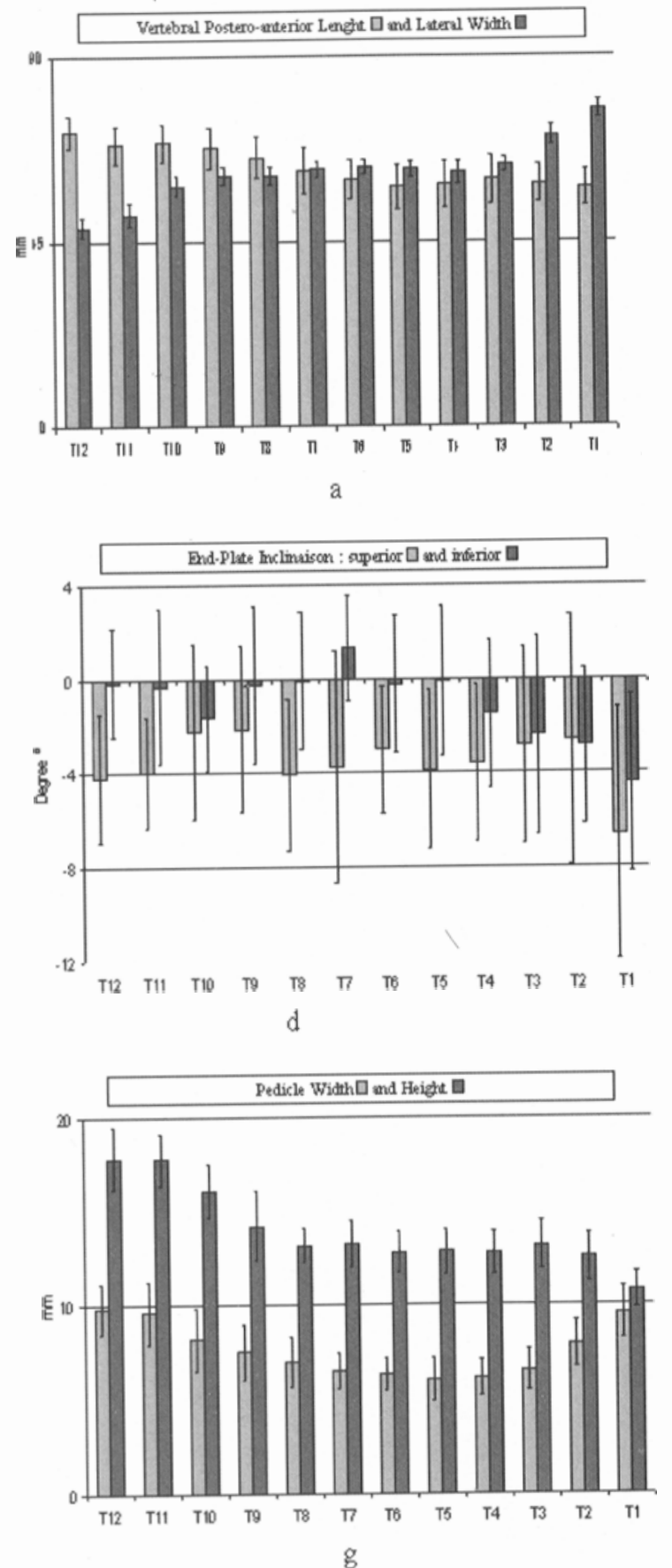
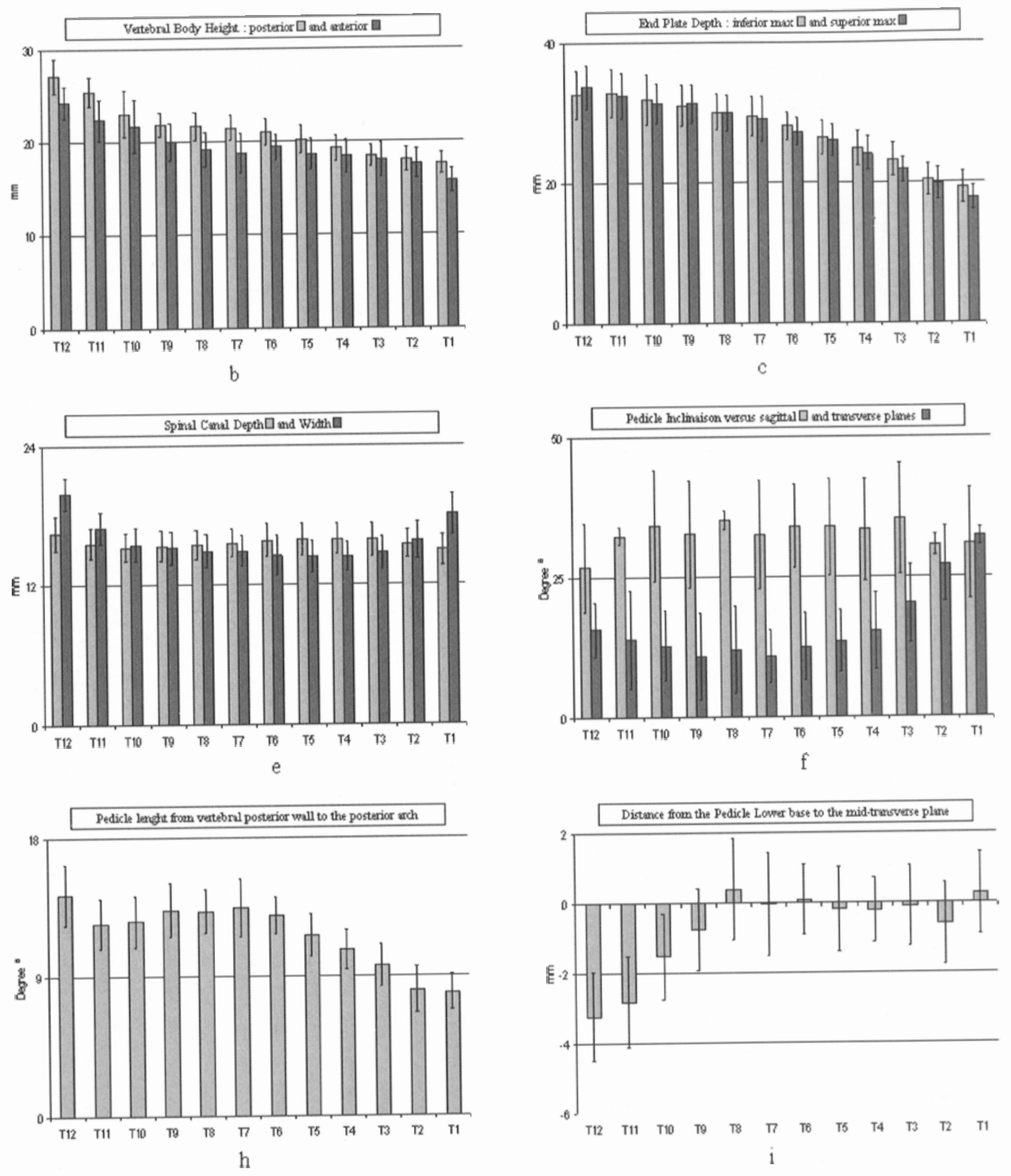
(from 82 to $76^{\circ}$ with standard deviations ranging from 6.7 to $\left.3.5^{\circ}\right)$ and then slightly decrease down to $\operatorname{T}_{1}\left(53, \sigma: 3.6^{\circ}\right)$. Facet surface range from 8.1 to $9.8 \mathrm{~mm}$ without a definite influence of the vertebral level (standard deviations lower than $2 \mathrm{~mm}$ ).

\section{Pedicles}

Figures 3-f to 3-i relate to pedicle dimension and orientation. For the sagittal plane pedicle orientation, variation is much more important among individuals (standard deviation is often greater than $7^{\circ}$ ) than among vertebral level (standard deviation close to $4^{\circ}$ ). As for the transverse plane pedicle orientation, mean values decrease from $T_{12}(15, \sigma$ : $\left.4.8^{\circ}\right)$ to $\mathrm{T}_{7}\left(10, \sigma: 4.7^{\circ}\right)$ then increase to $\mathrm{T} 1\left(32, \sigma: 1.5^{\circ}\right)$. Pedicle width is minimal between $\mathrm{T}_{7}$ and $\mathrm{T}_{3}$ with mean values lower than 7 (standard deviation ranging from 0.9 to 1.1$) \mathrm{mm}$ and values less than $5 \mathrm{~mm}$ for $10 \%$ of the specimens. Then pedicle width increase while going to the extreme levels of the thoracic spine to reach $9.8(\sigma: 1.3) \mathrm{mm}$ at T12 level and $9.7(\sigma: 1.4) \mathrm{mm}$ at $\mathrm{T} 1$ level. As for pedicle height it varies from 17.4 ( $\sigma: 1.7)$ $\mathrm{mm}$ at $\mathrm{T} 12$ level to $13.2(\sigma: 0.9) \mathrm{mm}$ at $\mathrm{T} 8$ level then remains quasi-constant from $\mathrm{T} 8$ to $\mathrm{T} 2$ the value at $\mathrm{T}_{1}$ being lower $(10.8, \sigma: 0.9 \mathrm{~mm})$. Standard deviation is about $3 \mathrm{~mm}$ for all the levels.

Pedicle length from the vertebral wall to the posterior arch is shown figure 3.i. Mean value is about $13 \mathrm{~mm}$ in the lower thoracic spine from $T_{11}(12.4, \sigma: 1.1$ $\mathrm{mm})$ to $\mathrm{T} 7 \mathrm{(13.4,}, 0: 1.9 \mathrm{~mm})$, it is slightly higher on $\mathrm{T}_{12}(14.3, \sigma: 2 \mathrm{~mm})$ and it decreases from $\mathrm{T}_{7}$ to $\mathrm{T}_{1}(7.9, \sigma: 1.1 \mathrm{~mm})$. Pedicle basis is located under the level of the mid-transverse plane for $\mathrm{T}_{12}$ and $\mathrm{T}_{11}$ (respectively $3.2, \sigma: 1.3 \mathrm{~mm} ; 2.8, \sigma: 1.3$ $\mathrm{mm}$ ), while it is on this plane level for the upper thoracic spine from $\mathrm{T} 9$ to $\mathrm{T} 1$.

Fig. 3

Examples of parameters variations according to the vertebral level

Table 2. Example of correlation coefficients and estimated errors results for some parameters

\begin{tabular}{|c|c|c|c|c|}
\hline \multirow[t]{2}{*}{ Parameters } & \multicolumn{2}{|c|}{ Estimated error $(\mathrm{mm})$} & \multicolumn{2}{|c|}{ Correlation coefficient } \\
\hline & Max & Min & $\operatorname{Max}$ & Min \\
\hline \multicolumn{5}{|c|}{ Estimated error lower than $2 \mathrm{~mm}$} \\
\hline PDW & 1.51 & 0.48 & 0.98 & 0.69 \\
\hline$C A$ inf $Y$ & 1.54 & 0.48 & 0.96 & 0.70 \\
\hline CA sup Y & 1.64 & 0.35 & 0.99 & 0.74 \\
\hline $\mathrm{PDH}$ & 1.66 & 0.49 & 0.99 & 0.75 \\
\hline SCD & 1.78 & 0.90 & 0.93 & 0.75 \\
\hline$C A \sup Z$ & 1.83 & 0.23 & 1.00 & 0.81 \\
\hline$C A$ sup $X$ & 1.84 & 0.57 & 0.99 & 0.77 \\
\hline$C A \inf X$ & 1.92 & 0.86 & 0.98 & 0.88 \\
\hline PDZ & 1.98 & 0.40 & 0.99 & 0.64 \\
\hline \multicolumn{5}{|c|}{ Estimated error lower than $3 \mathrm{~mm}$} \\
\hline$C A \inf Z$ & 2.91 & 0.77 & 0.97 & 0.71 \\
\hline \multicolumn{5}{|c|}{ Estimated error greater than $3 \mathrm{~mm}$} \\
\hline SPL & 5.79 & 0.37 & 1.00 & 0.37 \\
\hline \multicolumn{5}{|c|}{ Estimated error lower than $2 \mathrm{~mm}^{2}$} \\
\hline EPA sup & 0.99 & 0.24 & 1.00 & 0.95 \\
\hline FCA inf & 1.32 & 0.33 & 0.99 & 0.61 \\
\hline FCA sup & 1.57 & 0.35 & 0.98 & 0.70 \\
\hline EPA inf & 1.60 & 0.15 & 1.00 & 0.15 \\
\hline \multicolumn{5}{|c|}{ Estimated error lower than $6^{\circ}$} \\
\hline PDL & 1.85 & 0.47 & 0.99 & 0.72 \\
\hline \multicolumn{5}{|c|}{ Estimated error greater than $6^{\circ}$} \\
\hline TA sup & 7.04 & 0.49 & 1.00 & 0.55 \\
\hline SA sup & 7.20 & 1.36 & 0.99 & 0.66 \\
\hline TA inf & 8.76 & 0.56 & 1.00 & 0.68 \\
\hline PDIh & 12.08 & 2.6 & 0.98 & 0.56 \\
\hline PDIs & 15.21 & 2.07 & 0.99 & 0.71 \\
\hline SA inf & 18.23 & 2.48 & 0.95 & 0.46 \\
\hline
\end{tabular}

\section{Preliminary statistical results}

Multi-linear correlation coefficient and estimated error were calculated for each multi-linear relation (Table 2). All the 15 parameters are needed to explain $100 \%$ of the variability for each calculated parameter (result of the PCA). The results were separated in families depending of the estimated error on the calculated parameter: less than $\pm 2 \mathrm{~mm}$, less than $\pm 3 \mathrm{~mm}$ and more than $\pm 3 \mathrm{~mm}$ for the linear parameters, less and more than $\pm 6^{\circ}$ for the angular ones. All the surfacic parameters were estimated with an error less than $2 \mathrm{~mm}$. High correlation was found for some parameters, such as interarticularis facet position, pedicles height and width, with the dimensions of the vertebral bodies.

\section{Discussion}

Our results were compared when possible to existing published data $[1,2,4$, $9,10,11]$ and a global coherence was found, particularly with those of Panjabi [9], Berry [1] and Zindrick [11] for pedicle dimensions. As an example, our values for the Inferior End Plate Maximum Depth (EPD inf max, figure 4-a) are included in a corridor defined by other authors' results. However, for some parameters (mainly SCW Spinal canal width, and VBHP, posterior vertebral body height), although the general evolution is similar along the thoracic spine, large differences occur among published data; in the case of the Spinal Canal Width (SCW, figure 

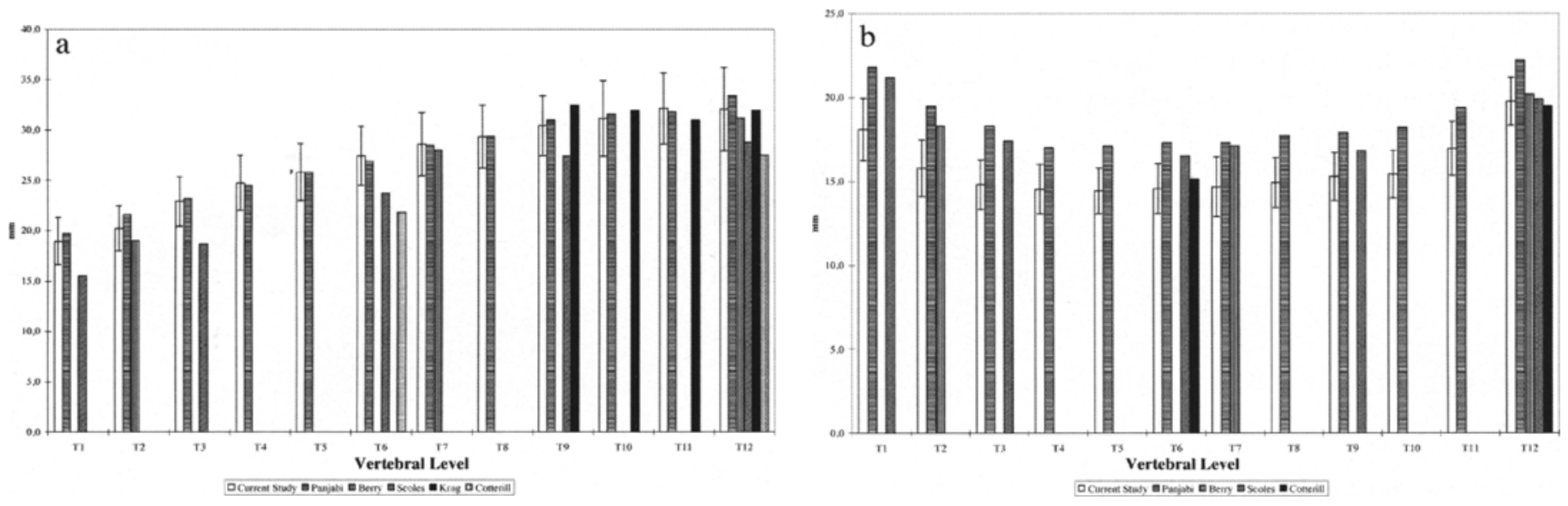

Fig. 4

Example of comparison between current (mean and standard deviation) and published mean values for a) inferior endplate maximum depth and b) spinal canal width

4-b), great differences can be noted, our values being generally smaller than the others, although they are close to Cotteril's ones [2]. This may be due either to a different definition of the same parameter for each author or to the protocol of preparation and measurement. Therefore, care must be kept when dealing with the two above mentioned parameters, where no definite value is yielded. However, for most of the parameters describing thoracic vertebrae, reliable mean values can be assessed from combination of various published data, including ours. The sample size give confidence both in the orders of magnitude and in the range of variation yielded by the study for the different parameters, although we cannot be certain that the sample is fully representative of the whole adult population without spinal pathology.

As for the statistical study, 15 main parameters were retained. However we assessed that only 10 regression parameters can explain $98.5 \%$ of the variability for each calculated parameters (PCA results), our choice was to use all the 15 initial parameters in order to keep the maximum of information from the X-Rays. This study assessed that various parameters can be calculated from the X-Rays with a reasonable accuracy, particularly articular surfaces are estimated with an error less than $2 \mathrm{~mm}$. A further investigation is necessary to refined correlation with a limited set of regression parameters.

\section{Conclusion}

A quantitative morphometric study and preliminary statistical analysis of the thoracic spine from $\mathrm{T}_{1}$ to $\mathrm{T}_{12}$ was conducted on 50 dried spines, with at least 20 vertebrae per level. The objectives were to quantify anatomic descriptive parameters concerning thoracic vertebrae, and to investigate statistical correlation between some of them. It therefore refines our knowledge of some dimensions and orientations for clinical applications, aid for implant's designing, and, to improve existing geometric and mechanical models or $3 \mathrm{D}$ reconstruction techniques concerning thoracic spine.

Acknowledgements: The authors would like to acknowledge Mr. Y. Lambert and Mr. M. Keita for their contribution to the statistical analysis and Mr. W. Koubaa for his contribution to the measurements.

\section{References}

1. Berry JL, Moran JM, Berg WS, Steffee AD (1987) A Morphometric Study of Human Lumbar and Selected Thoracic Vertebae. Spine, Vol 12, $\mathrm{N}^{\circ} 4$, pp 362-367

2. Cotteril PC, Kostuik JP, D'Angelo G, Fernie GR, Maki BE (1986) An anatomical comparison of the human and bovine thoracolumbar spine. J Orthop Res, 1986, Vol 4, pp 298-303

3. Koubaa W, Defives T, Pierunek M, Simonet J, Skalli W, Lavaste F (1995) Modélisation tridimensionnelle par éléments finis de la jonction thoraco-lombaire. Rachis, $\mathrm{Vol} 7, \mathrm{~N}^{\circ} 4$, pp $181-196$
4. Krag MH, Weaver DL, Beynnon BD, Haugh LD (1988) Morphometry of the Thoracic and Lumbar Spine Related to Transpedicular Screw Placement for Surgical Spinal Fixation. Spine, 1988, Vol 13, $\mathrm{N}^{\circ} 1$, pp 27-32

5. Landry C, De Guise I, Dansereau J, Labelle H, Skalli W, Zeller R, Lavaste F (1997) Analyse infographiqye des déformations tridimensionnelles des vertèbres scoliotiques. Annales de Chirurgie, Vol 51, $\mathrm{N}^{\circ} 8$, pp 867874

6. Landry C, Labelle H, Dansereau J, Liberge J, Asher M, De Guise J (1998) Morphometric characteristics of the scoliotic spine. Annales de Chirurgie, Vol 52, $\mathrm{N}^{\circ} 8$, pp 784-790

7. Le borgne P, Skalli W, Stokes IAF, Maurel N, Duval Beaupere G, Lavaste F (1995) Threedimensional measurment of a scoliotic spine. Three Dimentionnal Analysis of Spinal deformities. M D'Amico, A Merolli, GC Santambrogio IOS, pp 107-112

8. Mitton D, Landry C, Véron S, Skalli W, Lavaste F, De Guise JA. A 3 D reconstruction method from biplanar radiography using non stereocorresponding points and elastic deformable meshes. Med Biol Eng Comput, in press

9. Panjabi MM, Takata K, Goel V, et al. (1991) Thoracic Human Vertebrae Quantitative Three-Dimensional Anatomy. Spine, Vol 16, $\mathrm{N}^{\circ} 8$, pp 888-901

10. Scoles PV, Linton AE, Buce L, Ievy ME, Bigiovanni BF (1988) Vertebral Body and Posterior Element Morphology: The Normal Spine in Middle Life. Spine, Vol 13, $\mathrm{N}^{\circ}$ 10, pp 1082-1086

11. Zendrick MR, Wiltse LL, Doornik A, Widell E.H, Knight GW, Patwardhan AG, Thomas JC, Rothman SL, Fields BT (1987) Analysis of the morphometric characteristics of the thoracic and lumbar pedicles. Spine, $\mathrm{Vol}{ }_{12}, \mathrm{~N}^{\circ}{ }_{1}$, pp 160-166 
Resume: Travail realise: Une etude morphometrique quantitative de la colonne thoracique, de T1 a T12, a ete realisee sur 50 colonnes vertebrales seches. Objectifs : Quantifier les parametres anatomiques decrivant la vertebre thoracique et analyser les correlations statistiques existant entre eux, clans le but 1) d'approfondir les connaissances sur certaines dimensions et orientations pour des applications cliniques, 2) d'aider a la conception d'implants, et, 3) d'ameliorer les modeles geometriques et mecaniques existants ainsi que les techniques de reconstruction $3 \mathrm{D}$ de la colonne thoracique. Resume de la bibliographie: Peu d'etudes quantitatives tridimensionnelles concernent des vertebres thoraciques, et celles-ci ne s'interessent qu'a un nombre limite de parametres ou ne sont realisees que sur des series limitees de specimens. Aucune recherche sur les correlations statistiques entre parametres n'a ete encore realisee pour les vertebres thoraciques. Methodes: 373 vertebres thoraciques provenant de 50 colonnes ont ete considerees. Les coordonnees spatiales de 140 points disperses sur la surface de chaque vertebre (130 pour Tio et 120 pour Tn et T12) ont ete relevees grace a un systeme de mesure electromagnetique (FASTRAK@ , precision estimee: $\pm 0,4 \mathrm{~mm}$ ). Les parametres descriptifs ont ete alors calcules avec $\mathrm{EXCEL}^{\varpi}$ et les correlations statistiques ont ete etudiees avec xlSTAT ${ }^{\circledast}$. Resultats: les moyennes ainsi que les ecarts types ont ete obtenus pour 81 parametres lineaires, surfaciques ou angulaires, pour chacun des niveaux vertebraux thoraciques. De fortes correlations ont ete decouvertes entre certains parametres, tels que la localisation des facettes articulaires ou la largeur et la hauteur des pedicules, et les dimensions du corps vertebral, qui sont accessibles sur des radiographies. Conclusion : Une description fine et detaillee de la vertebre thoracique est fournie. Pour la premiere fois, une correlation statistique est demontree entre quelques parametres descriptifs, visibles a la radiographie, et d'autres qui ne le sont pas.

Mots des : Vertebres thoraciques - Morphometrie - Correlations 